\title{
Trends of inflammatory bowel disease at a tertiary care center in northern India
}

\author{
Ajit Sood ${ }^{1}$, Kirandeep Kaur ${ }^{2}$, Arshdeep Singh ${ }^{1}$, Vandana Midha ${ }^{3}$, Ramit Mahajan ${ }^{1}$, Namita Bansal ${ }^{4}$, Varun Mehta ${ }^{1}$, \\ Dharmatma Singh $^{4}$ \\ Departments of ${ }^{1}$ Gastroenterology, ${ }^{2}$ Pharmacology, and ${ }^{3}$ Internal Medicine, ${ }^{4}$ Research and Development Centre, Dayanand Medical College \\ and Hospital, Ludhiana, India
}

Background/Aims: Inflammatory bowel disease (IBD), including ulcerative colitis (UC) and Crohn's disease (CD), is increasingly being reported from India and other Asian countries. This study looks into the changing trends of IBD at a tertiary care center in north India over last two decades. Methods: Retrospective analysis of a prospectively maintained database of patients diagnosed with IBD between January 1991 and December 2015 was conducted. The study period was divided into five times cohorts (1991-1995, 1996-2000, 2001-2005, 2006-2010, 2011-2015). Results: During the study period, 2,467 patients (UC $[\mathrm{n}=2,137,86.6 \%], \mathrm{CD}[\mathrm{n}=330,13.3 \%]$, mean age $38.5 \pm 13.3$ years; $55.9 \%$ males) were registered. The proportion of patients with CD increased (ratio of UC to CD declined from 15.7:1 to 4:1). The mean age at diagnosis decreased for UC (45.7 \pm 12.1 years in 1991-1995 vs. $37.6 \pm 13.0$ years in $2011-2015 ; P=0.001)$ and remained consistent for CD $(41.3 \pm 13.6$ years in $1996-2000$ vs. $41.3 \pm 16.9$ years in $2011-2015, P=0.86)$. Patients with proctitis in UC and isolated ileal disease in CD increased over the study period $(P=0.001$ and $P=0.007$, respectively). Inflammatory CD increased $(P=0.009)$ whereas stricturing CD decreased $(P=0.01)$ across all cohorts. There was a trend towards less severe presentation of both UC and CD. The use of thiopurines $(P=0.02)$ and biologics increased $(P=0.001)$ with no significant change in trends for requirements of surgery $(P=0.9)$. Conclusions: Increasing prevalence of $\mathrm{CD}$, younger age at diagnosis, diagnosis at an earlier and milder stage, greater use of thiopurines and biologics were observed. (Intest Res 2021;19:282-290)

Key Words: Inflammatory bowel disease; Ulcerative colitis; Trends; Crohn disease; India

\section{INTRODUCTION}

Inflammatory bowel disease (IBD) is a chronic relapsing and remitting disorder that consists majorly of Crohn's disease (CD) and ulcerative colitis (UC). Traditionally, IBD has been considered to be a disease of the West; however, there is convincing evidence of rising trend of IBD in Asian countries; India probably heading the list. ${ }^{1-6}$ Epidemiological studies from Asian countries have shown important differences in the de-

Received January 20, 2020. Revised May 1, 2020. Accepted May 1, 2020. Correspondence to Kirandeep Kaur, Department of Pharmacology, Dayanand Medical College and Hospital, Tagore Nagar, Civil Lines, Ludhiana 141001, India. Tel: +91-9815-277-755, Fax: +91-161-2302620, E-mail:

kiransondhi@gmail.com mographic profile, disease course and clinical outcomes as compared to the Western countries, which may be attributed to the differences in the genetic makeup and impact of environmental factors. ${ }^{7}$ In the past years, paralleling the increase in prevalence of IBD, have been major advances both in understanding disease pathogenesis and developing newer diagnostic and therapeutic agents. Changes in lifestyle and diet associated with urbanization and industrialization of societies have resulted in a major paradigm shift in the disease presentation and behavior of IBD. The present study looks into the epidemiological trends in patients diagnosed with IBD at a tertiary care hospital in northern India. 


\section{METHODS}

\section{Study Design}

This is a single-center retrospective, observational, cross-sectional hospital-based epidemiological study conducted at Dayanand Medical College and Hospital, Ludhiana, India over a period of 25 years, between January 1, 1991 and December 31,2015 . The study was approved by the Institutional Review Board (IRB No. DMCH/R\&D/2020/23). The informed consent was waived.

\section{Study Population}

All confirmed patients of IBD (UC or CD) presenting to Department of Gastroenterology at Dayanand Medical College and Hospital, Ludhiana, between January 1, 1991 and December 31, 2015 were included. Diagnosis of IBD was established on the basis of Copenhagen (clinical, laboratory, radiological, and pathological) criteria. ${ }^{8,9}$ The medical record of each patient was retrieved from prospectively maintained database and the patients' demographic profile (including age at diagnosis, gender), disease history including disease duration, disease behavior and severity, extent of disease, complications, drugs prescribed and requirement of surgery were recorded. Montreal classification was used to assess the disease phenotype in adults with $\mathrm{IBD}^{10}$ whereas Paris classification was used for patients in pediatric age group $(<17$ years) (Supplementary Tables 1, 2). ${ }^{11}$ Disease severity was defined by the Mayo score in patients with UC patients ${ }^{12}$ and Crohn's Disease Activity In$\operatorname{dex}(\mathrm{CDAI})$ in patients with $\mathrm{CD}^{13}$

Patients were divided into 5 cohorts each of 5 years starting from 1991; i.e., January 1991 to December 1995, January 1996 to December 2000, January 2001 to December 2005, January 2006 to December 2010, January 2011 to December 2015. Patients with missing data were not included in the analysis.

\section{Statistical Analysis}

Data were described in terms of range; mean \pm standard deviation, median, frequencies (number of cases) and relative frequencies (percentages) as appropriate. Comparison of quantitative variables between the study groups was done using analysis of variance. For comparing categorical data, chisquare test was performed and exact test was used when the expected frequency was less than 5 . The Jonckheere-Terpstra and Cuzick method were used to test trend across different time period for categorical variables. A probability value $(P$ value) less than 0.05 was considered statistically significant.
All statistical calculations were done using SPSS version 21 (IBM Corp., Armonk, NY, USA) and Stata version 12 (StataCorp., College Station, TX, USA).

\section{RESULTS}

During the study period (January 1991 to December 2015), a total of 2,467 patients (mean age, $38.5 \pm 13.3$ years; $55.9 \%$ males, $\mathrm{n}=1,380$ ) were diagnosed with IBD ( $86.6 \%$ of UC $[\mathrm{n}=2,137]$, mean age $38.1 \pm 13.0$ years, $55.1 \%$ of males $[n=1,178]$ and $13.37 \%$ of $\mathrm{CD}[\mathrm{n}=330]$, mean age $41.2 \pm 15.1$ years, $61.2 \%$ of males $[n=202]$ ).

\section{Temporal Trends of IBD Occurrence}

As is evident from Fig. 1, the number of IBD patients, especially $\mathrm{CD}$, increased over the entire study period. The number of patients with UC increased till 2005 after which the numbers plateaued. Though the disease burden continued to be high, the overall trend for patients presenting with UC stabilized $\left(\mathrm{R}^{2}=0.5485\right)$. In contrast the number of patients with $\mathrm{CD}$ witnessed a steep rise beginning 2001 and the trend continued till the last time cohort $\left(\mathrm{R}^{2}=0.9073\right)$. This is also evident from the UC to CD ratio that declined from 15.7:1 in 1996-2000 cohort (the first case of CD was diagnosed in 1996) to 4:1 in 2011-2015 cohort (Fig. 1).

\section{Demographic Profile}

\section{1) Age}

The mean age at diagnosis in patients with UC was $38.1 \pm 13.0$ years compared to $41.2 \pm 15.1$ years in patients with $\mathrm{CD}$. There was a trend towards UC presenting at a younger age over the

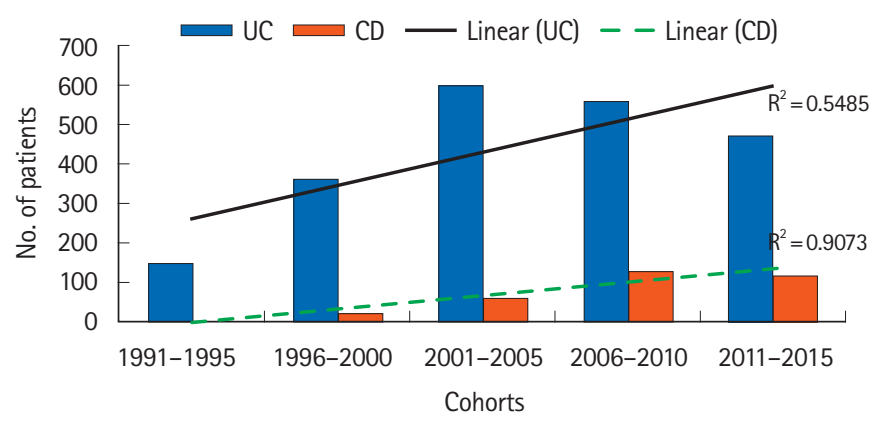

Fig. 1. Temporal trends in occurrence of inflammatory bowel disease (1991-2015). $R^{2}$ : Coefficient of determination (0\% indicates that the model explains none of the variability of the response data around its mean. 100\% indicates that the model explains all the variability of the response data around its mean). UC, ulcerative colitis; $C D$, Crohn's disease. 
entire study period (1991-1995 mean age, $45.7 \pm 12.1$ years vs. 2011-2015 mean age, 37.6 $\pm 13.0 ; P$ for trend $=0.001$ ). On the other hand, there was no significant change in the mean age of disease diagnosis over the 4 cohorts for patients with CD (1996-2000 mean age, 41.3 \pm 13.6 years vs. 2011-2015 mean age, $41.3 \pm 16.9$; $P$ for trend $=0.86$ ).

The proportion of patients with pediatric IBD (age $<17$ years) remained consistent for both UC and CD over the two decades ( $P$ for trend $=0.78$ and 0.89 respectively). Proportion of elderly patients (age $>60$ years) presenting with UC also did not change significantly ( $P$ for trend $=0.98$ ). However, the proportion of elderly onset CD increased from 8.7\% $(n=2)$ in 19962000 cohort to $19.6 \%(\mathrm{n}=23)$ in $2011-2015$ cohort $(P$ for trend $=$ 0.04) (Table 1).

\section{2) $\operatorname{Sex}$}

Fifty-six percent of patients of the total cohort were males. The male to female ratio for UC and CD were 1.22:1 and 1.57:1 respectively over the entire study period. The proportion of males with IBD increased from $49.7 \%$ in 1991-1995 to $59.6 \%$ in $2011-$ 2015 ( $P$ for trend $=0.033$ ). The increasing incidence of disease in males was more evident for UC (49.7\% in 1991-1995 vs. $57.6 \%$ in 2011-2015; $P$ for trend $=0.006$ ) as compared to CD (65.2\% in $1996-2000$ vs. $67.5 \%$ in $2011-2015$; $P$ for trend $=0.317$ ).

\section{Disease Location and Extent}

Out of 2,137 patients with UC, majority $(55.4 \%, n=1,185)$ had left-sided colitis. Pancolitis and proctitis were noted in 23.1\% $(\mathrm{n}=493)$ and $14.4 \%(\mathrm{n}=309)$ patients. The disease extent was not known in $7 \%(\mathrm{n}=150)$ patients. When the trends were analyzed over the entire study period, proportion of patients presenting with proctitis increased from $9.4 \%$ (1991-1995) to 28.6\% (2011-2015) ( $P$ for trend $=0.001)$ whereas patients presenting with pancolitis decreased from $33.6 \%$ (1991-1995) to $16.9 \%(2011-2015)$ ( $P$ for trend $=0.001)$. Most of the patients in each cohort had left-sided colitis and the trend has not changed ( $P$ for trend $=0.07$ ) (Fig. 2A).

Isolated ileal disease was the most common $(45.5 \%, \mathrm{n}=150)$

Table 1. Trends in Age at Diagnosis of Inflammatory Bowel Disease (1991-2015)

\begin{tabular}{|c|c|c|c|c|c|c|c|c|c|c|c|}
\hline \multirow{2}{*}{$\begin{array}{l}\text { Age at } \\
\text { diagnosis }\end{array}$} & \multicolumn{2}{|c|}{ 1991-1995 } & \multicolumn{2}{|c|}{ 1996-2000 } & \multicolumn{2}{|c|}{ 2001-2005 } & \multicolumn{2}{|c|}{ 2006-2010 } & \multicolumn{2}{|c|}{ 2011-2015 } & \multirow{2}{*}{ Total } \\
\hline & UC & $\mathrm{CD}$ & UC & CD & UC & CD & UC & CD & UC & CD & \\
\hline \multicolumn{12}{|l|}{ Age (yr) } \\
\hline$<17$ & $8(5.4)$ & - & $23(6.3)$ & $2(8.7)$ & $35(5.9)$ & $3(4.9)$ & $32(5.7)$ & $3(2.3)$ & $30(6.3)$ & $4(3.41)$ & $140(5.7)$ \\
\hline $17-60$ & 138 (92.6) & - & 325 (89.8) & 19 (82.6) & 536 (89.9) & 49 (79.0) & 501 (89.8) & 113 (88.3) & 421 (89.2) & 90 (76.9) & 2,192 (88.8) \\
\hline$>60$ & $3(2.0)$ & - & 14 (3.9) & $2(8.7)$ & $25(4.2)$ & $10(16.1)$ & $25(4.5)$ & 12 (9.4) & $21(4.5)$ & 23 (19.6) & $135(5.5)$ \\
\hline Mean age (yr) & $45.7 \pm 12.1$ & - & $37.8 \pm 12.8$ & $41.3 \pm 13.6$ & $38.1 \pm 12.9$ & $41.3 \pm 16.3$ & $37.2 \pm 13.1$ & $41.0 \pm 13.1$ & $37.6 \pm 13.0$ & $41.3 \pm 16.9$ & \\
\hline
\end{tabular}

Values are presented as number (\%) or mean \pm standard deviation.

UC, ulcerative colitis; CD, Crohn's disease.
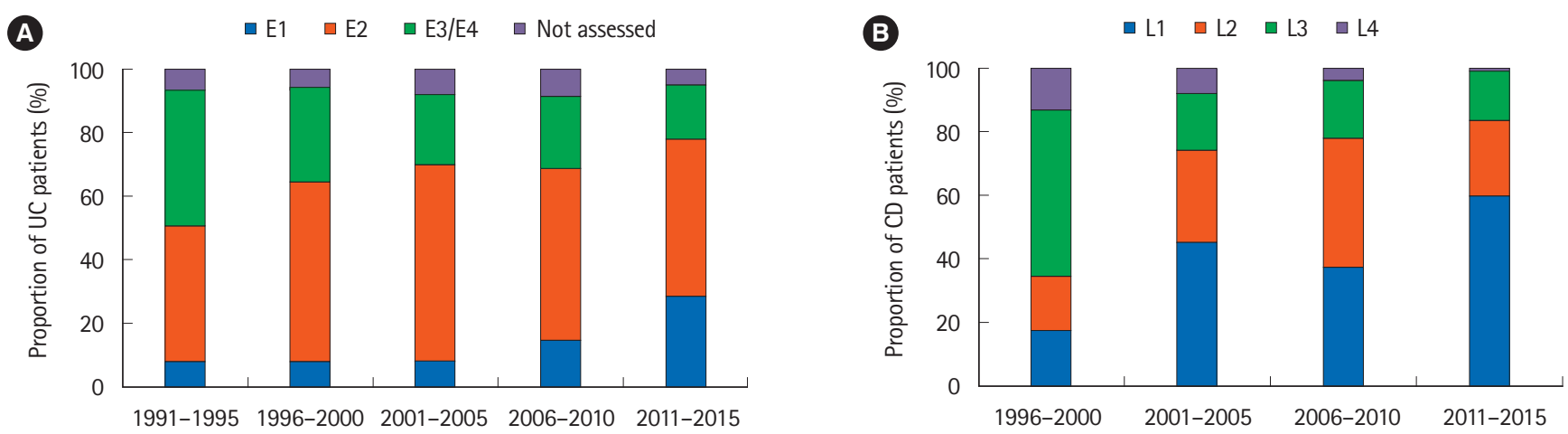

Fig. 2. Trends in disease extent and location (1991-2015). (A) Disease extent in ulcerative colitis. (B) Disease location in Crohn's disease. E1, proctitis; E2, left-sided colitis; E3, disease extending proximal to splenic flexure including pancolitis for adult patients, disease extending proximal to splenic flexure but distal to hepatic flexure for pediatric patients; E4, disease extending proximal to hepatic flexure in pediatric patients; L1, ileal disease; L2, colonic; L3, ileocolonic; L4, isolated upper disease. 
disease location in patients with CD followed by colonic (30.9\%, $\mathrm{n}=102)$, ileocolonic $(19.4 \%, \mathrm{n}=64)$ and isolated upper GI tract $(4.2 \%, \mathrm{n}=14)$ involvement. Perianal fistulizing disease was seen in $2.7 \%$ patients $(\mathrm{n}=9)$ only. Isolated ileal disease showed an increasing trend $(P$ for trend $=0.007$ ) whereas ileocolonic and upper gastrointestinal involvement decreased $(P$ for trend $=$ 0.004 and 0.002 respectively) over entire study cohort (Fig. 2B).

\section{Disease Behavior CD}

Inflammatory disease (B1) was the commonest disease phenotype seen in $77.9 \%(n=257)$ of all patients, followed by stricturing disease (B2) and fistulizing disease (B3) which were seen in $18.2 \%(\mathrm{n}=60)$ and $3.9 \%(\mathrm{n}=13)$ of all patients, respectively. Proportion of patients with inflammatory disease increased across the cohorts $(P$ for trend $=0.009$ ) whereas stricturing disease decreased $(P$ for trend $=0.014)$ (Fig. 3 ).

\section{Disease Severity}

Eighty-three percent of patients with UC had moderately se-

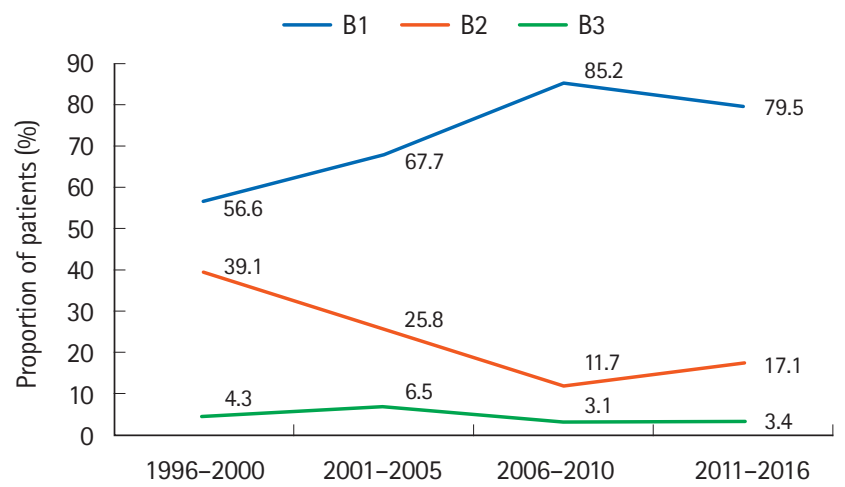

Fig. 3. Trends in disease behavior in Crohn's disease (1996-2015). B1, non-penetrating, non-stricturing disease; B2, stricturing disease; B3, penetrating disease.

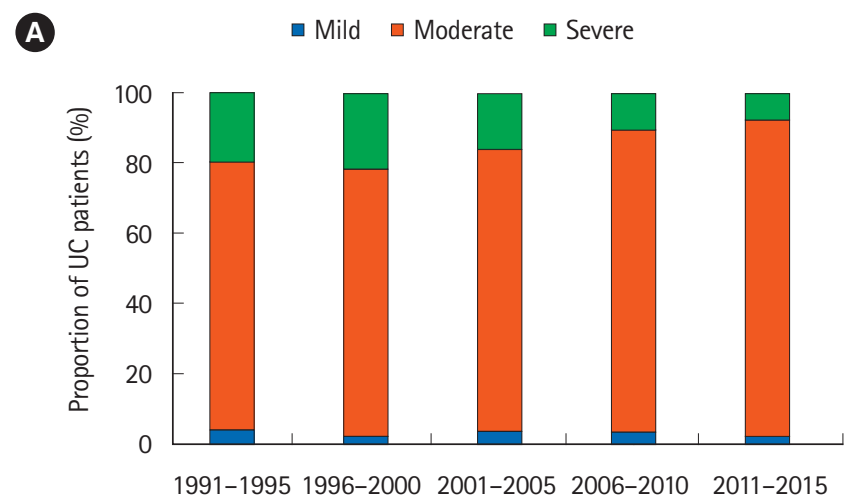

vere (Mayo score 6-9) disease. Severe disease (mayo score $\geq 10)$ was recorded in $14 \%$ patients $(n=299)$. Across the cohorts, severe disease declined (19.5\% in 1991-1995 to $7.6 \%$ in 2011-2015; $P$ for trend $=0.001)$. Proportion of patients with moderate disease increased $(P$ for trend $=0.001)$ and mild disease did not change significantly $(P$ for trend $=0.628)($ Fig. 4$)$.

Majority of the patients $(70 \%, \mathrm{n}=231)$ with $\mathrm{CD}$ had moderate-severe disease (CDAI, 220-450) followed by mild-moderate disease activity (CDAI, 150-220; $\mathrm{n}=78,23.6 \%$ ). Severe disease (CDAI $>450)$ was recorded in $6.4 \%$ patients $(\mathrm{n}=21)$ (Fig. 4 ). There was a trend towards less severe presentation of $\mathrm{CD}$ across all the cohorts over the study period (mild-moderate [increasing] and severe/fulminant [decreasing] disease; $P$ for trend $=0.007$ and 0.001 , respectively).

\section{Treatment}

All patients with IBD received 5-aminosalicylic acid agents (5ASA), either oral or topical, for treatment across all cohorts. However, 10 patients $(0.4 \%)$ showed paradoxical worsening of diarrhea ( $n=3)$, hypersensitivity $(n=3)$, allergic bronchitis $(\mathrm{n}=3)$, and pancreatitis $(\mathrm{n}=1)$ with use of 5-ASA and the same was discontinued. Thiopurines (azathioprine/6-mercaptopurine) were more commonly used in CD than UC (73\% in CD vs. $34.2 \%$ in UC, $P=0.001$ ). However, there was an increasing trend in the use of thiopurines, from $29.5 \%$ in 1991-1995 to $43.4 \%$ in $2011-2015$ cohort in patients with UC ( $P$ for trend $=$ 0.028). The use in CD remained stable across all the cohorts ( $P$ for trend $=0.156$ ).

Cyclosporine in patients with UC was used predominantly in 2 cohorts, 2001-2005 and 2006-2010 ( $\mathrm{n}=18,3.0 \%$ and $\mathrm{n}=7$, $1.3 \%)$. However, the trend declined rapidly after that with only 1 patient $(0.2 \%)$ treated with cyclosporine in 2011-2015 time cohort. This decline in usage of cyclosporine was paralleled by

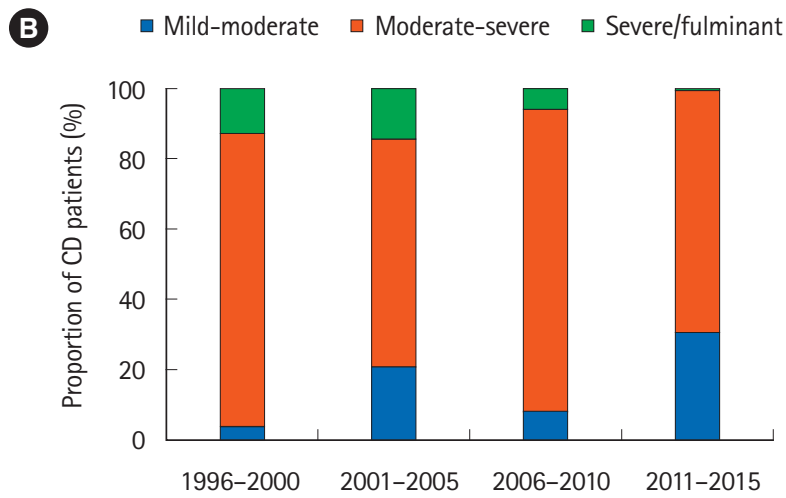

Fig. 4. Trends (1991-2015) in disease severity of ulcerative colitis (UC) (A) and Crohn's disease (CD) (B). 
Table 2. Trends in Use of Biologics in Severe Inflammatory Bowel Disease (1991-2015)

\begin{tabular}{lcccccc}
\hline Disease behavior & $\mathbf{1 9 9 1 - 1 9 9 5}$ & $\mathbf{1 9 9 6 - 2 0 0 0}$ & $\mathbf{2 0 0 1 - 2 0 0 5}$ & $\mathbf{2 0 0 6 - 2 0 1 0}$ & $\mathbf{2 0 1 1 - 2 0 1 5}$ & Total \\
\hline UC & & & & & & \\
Severe disease & 29 & 78 & 96 & 60 & 36 & 299 \\
Use of biologics & $2(6.8)$ & $1(1.2)$ & $17(17.7)$ & $16(26.6)$ & $26(72.2)$ & $62(20.7)$ \\
CD & - & 3 & 9 & 8 & 1 & 21 \\
Severe disease & - & $2(66.6)$ & $3(33.3)$ & $4(50.0)$ & $1(100)$ & $10(47.6)$ \\
Use of biologics & & &
\end{tabular}

Values are presented as number or number (\%).

UC, ulcerative colitis; CD, Crohn's disease.
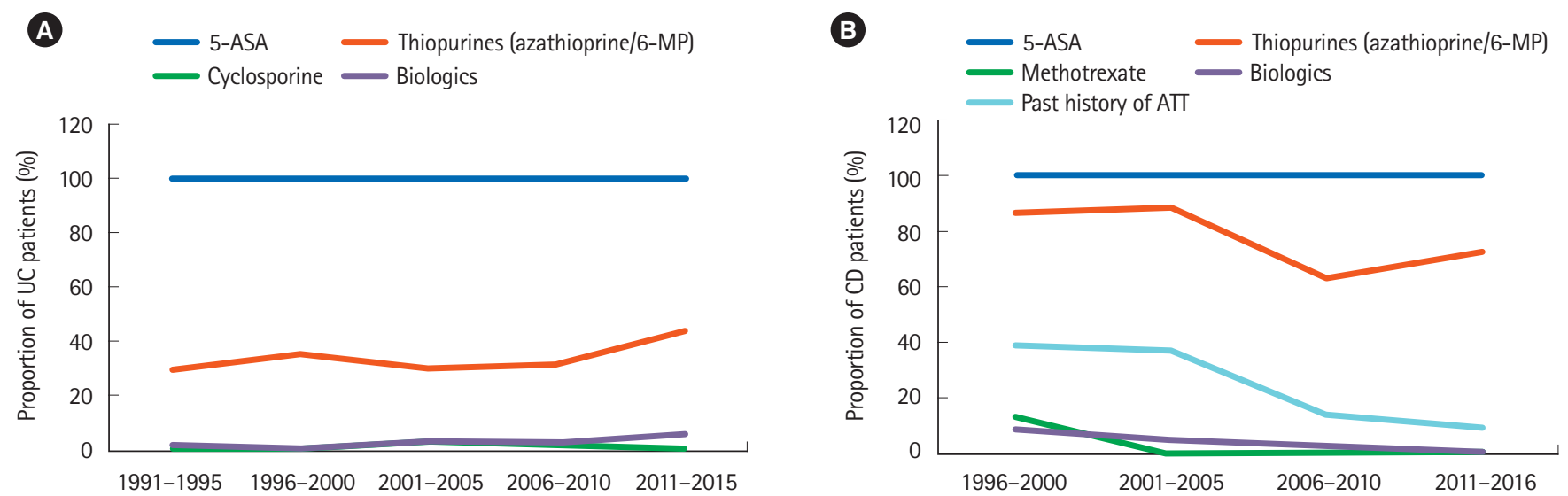

Fig. 5. Trends in usage of various pharmacological agents in inflammatory bowel disease (1991-2015). (A) Ulcerative colitis (UC) and (B) Crohn's disease (CD). 5-ASA, 5-aminosalicylic acid; 6-MP, 6-mercaptopurine; AT, antitubercular therapy.

increasing usage of biologics for patients with UC (anti-TNF agents: infliximab, infliximab biosimilar or adalimumab biosimilar, $1.3 \%$ [ $\mathrm{n}=2]$ in $1991-1995$ to $5.5 \%$ [ $\mathrm{n}=26]$ in $2011-$ 2015; $P$ for trend $=0.001)$. The overall use of biologics in severe disease was more for CD as compared to UC ( $47.6 \%$ vs. $20.7 \%$, $P=0.004$ ) (Table 2, Fig. 5).

Nearly one-fifth patients with $\mathrm{CD}(\mathrm{n}=61,18.5 \%)$ had received antitubercular therapy in past before the diagnosis of $\mathrm{CD}$ was established. Though the overall trend of use of antitubercular therapy was seen to decline ( $P$ for trend $=0.062$ ).

Seventy-five patients with UC (3.5\%) underwent surgery across all cohorts. The overall trend for requirement of surgery in UC remained stable ( $P$ for trend $=0.948$ ). The most common indication of surgery in UC was failure of medical therapy ( $70.7 \%, \mathrm{n}=53$ ) followed by development of colorectal carcinoma (CRC) $(18.7 \%, \mathrm{n}=14)$ and toxic megacolon $(9.3 \%, \mathrm{n}=7)$. The requirement of surgical intervention in $\mathrm{CD}$ declined over the study period (from 39.1\% in 1996-2000 to $4.3 \%$ in 2011-2015; $P$ for trend $=0.001$ ). Intestinal obstruction was the most common indication of surgery in $\mathrm{CD}(\mathrm{n}=39 / 52,75 \%)$.
Sixteen $(0.6 \% ; \mathrm{n}=14[0.6 \%]$ in UC and $\mathrm{n}=2[0.6 \%]$ in $\mathrm{CD})$ in the entire cohort developed CRC with no significant change in trend across the cohorts $(P$ for trend $=0.687)$ (Table 3 ).

\section{DISCUSSION}

IBD, once considered a disease of developed nations, has firmly established itself in developing countries, India in particular. The disease prevalence and incidence are amongst the highest in Asia. Though the crude incidence of IBD has not been calculated over the decades, the disease burden appears to be increasing placing a substantial clinical and economic burden on health services. The overall estimated IBD population in India in 2010 was 1.4 million, which was the second highest number after the United States (with 1.64 million). ${ }^{14}$ Key advancements in management of IBD along with greater awareness among clinicians have resulted in a major shift in approach to these patients.

This observational study conducted in northern India shows evolving pattern of disease and management practices 
Table 3. Trends in Surgical Intervention in Inflammatory Bowel Disease (1991-2015)

\begin{tabular}{|c|c|c|c|c|c|c|}
\hline Trends & 1991-1995 & $1996-2000$ & $2001-2005$ & 2006-2010 & 2011-2015 & Total \\
\hline Total UC patients underwent surgery & $9(6.0)$ & $13(3.6)$ & $15(2.5)$ & $12(2.2)$ & $26(5.5)$ & $75(3.5)$ \\
\hline \multicolumn{7}{|l|}{ Indication of surgery } \\
\hline Failure of medical therapy & $4(44.4)$ & $12(92.4)$ & $12(80.0)$ & $7(58.3)$ & $18(69.2)$ & $53(70.6)$ \\
\hline Malignancy & $3(33.3)$ & $1(7.6)$ & $2(13.3)$ & $4(33.3)$ & $4(15.4)$ & $14(18.7)$ \\
\hline Intestinal obstruction & - & - & - & - & - & - \\
\hline Intestinal perforation & $1(11.1)$ & - & - & - & - & $1(1.3)$ \\
\hline Toxic megacolon & $1(11.1)$ & - & $1(6.7)$ & $1(8.3)$ & $4(15.4)$ & $7(9.3)$ \\
\hline \multicolumn{7}{|l|}{ Type of surgery } \\
\hline Colectomy with stoma & $5(55.6)$ & $8(61.5)$ & $6(40.0)$ & $6(50.0)$ & $10(38.5)$ & $35(46.7)$ \\
\hline IPAA & $4(44.4)$ & $5(38.5)$ & $9(60.0)$ & $6(50.0)$ & $16(61.5)$ & $40(53.3)$ \\
\hline Total CD patients underwent surgery & - & $9(39.1)$ & $19(30.6)$ & $19(14.8)$ & $5(4.3)$ & $52(15.7)$ \\
\hline \multicolumn{7}{|l|}{ Indication for surgery } \\
\hline Intestinal obstruction & - & $7(77.8)$ & $15(78.9)$ & $14(73.7)$ & $3(60.0)$ & $39(75.0)$ \\
\hline Hemorrhage & - & $2(22.2)$ & - & $2(10.5)$ & - & $4(7.7)$ \\
\hline Malignancy & - & - & $1(5.3)$ & $1(5.3)$ & - & $2(3.8)$ \\
\hline Perianal fistula & - & - & $2(10.5)$ & - & - & $2(3.8)$ \\
\hline Intestinal perforation & - & - & $1(5.3)$ & $2(10.5)$ & $2(40.0)$ & $5(9.6)$ \\
\hline \multicolumn{7}{|l|}{ Type of surgery } \\
\hline Resection with anastomosis & - & $9(100)$ & $16(84.2)$ & $15(78.9)$ & $3(60.0)$ & $43(82.7)$ \\
\hline Strictureplasty & - & - & - & $3(15.8)$ & $1(20.0)$ & $4(7.7)$ \\
\hline Colectomy/hemicolectomy & - & - & $1(5.3)$ & $1(5.3)$ & - & $2(3.8)$ \\
\hline Drainage of perianal abscess/non-cutting seton placement & - & - & $2(10.5)$ & - & $1(20.0)$ & $3(5.8)$ \\
\hline
\end{tabular}

Values are presented as number (\%).

UC, ulcerative colitis; IPAA, ileal pouch anal anastomosis; CD, Crohn's disease.

over two and a half decades. There has been a steady increase in number of patients with IBD across the time cohorts (Fig. 1). Patients with UC outnumbered patients with $C D$. The exact reason why UC is more common in northern India as compared to southern India (where CD is more common) is not clear. However, the number of patients with $\mathrm{CD}$ has also increased steadily and significantly over time. Patients with UC on the other hand increased in the first 4 cohorts, followed by a decrease in the last cohort indicating a trend towards plateauing prevalence of UC. This is highlighted by the fact that UC to CD ratio decreased from 15:1 to 4:1 over the study period. These findings draw a corollary to the reports from West that demonstrate UC preceding CD in a population, and later, a decreased/reversed ratio of incidence rates of UC and $\mathrm{CD}^{15}$

The mean age of patients diagnosed with IBD decreased over the study period ( $45.7 \pm 12.1$ in the first cohort to $38.4 \pm 13.8$ in the last cohort). This was primarily due to a gradual decrease in age at presentation for UC as there was no significant change in the mean age of diagnosis for patients with CD over the time cohorts. However, when we look at proportion of patients with pediatric ( $<17$ years) or elderly onset $(>60$ years) IBD, it remained consistent indicating that the majority of patients ( $88.8 \%$ to be precise) belong to $18-60$ years age group. This may however not be an accurate observation because there was no pediatric gastroenterologist or geriatric physician involved as all the patients in electronic database had reported to adult gastroenterology clinics. Another interesting finding/ observation was UC presenting at a younger age than CD. This is in contrast to IBD in West that is characterized by CD occurring a decade earlier than UC. ${ }^{16,17}$ This is also in contradiction to a country-wide survey of IBD from India where the mean age at diagnosis of UC and CD was 38.5 and 35.9 years, respectively. This survey however had majority of CD patients (231/409, 56.4\%) from southern India and only 72 out of 409 patients (17.6\%) were from northern India and thus may not be truly representative of demographics in northern India. ${ }^{7}$ 
Also IBD has reached relatively late in developing countries including India. So as time lapses, IBD (both UC and CD) is expected to involve younger population. This epidemiological observation has also been documented in various populationbased studies following IBD populations for decades. ${ }^{18}$ Also severe $\mathrm{CD}$ was infrequent in the current study. Majority of the patients had mild-moderately severe disease. This could be one reason that population is older. As we start seeing severe disease (which is expected in India if we consider the epidemiological time tends observed in developed countries), younger age at diagnosis may be encountered. Also, intestinal tuberculosis is a close differential of $\mathrm{CD}$ in India. Many patients receive antitubercular therapy before they are finally diagnosed as $\mathrm{CD}$. Hence age at diagnosis is older.

Both UC and CD were more common in males. This is unlike $\mathrm{CD}$ in the West where females predominate. The increased prevalence of IBD in males could represent a unique Indian demographic pattern or could be secondary to a generalized social bias against females and lesser number of females reporting to tertiary care centers.

The phenotype of disease amongst Asian patients with IBD has been described to differ from that of patients from North America and Western Europe. Left-sided colitis (E2 disease) remained the commonest disease location in patients with UC in the current study. Proctitis (E1) however showed an increasing trend over time. The prevalence of patients with pancolitis decreased. This can be explained by increasing awareness among physicians and better diagnostic modalities picking up UC early in the disease course.

For CD, mild and isolated ileal disease showed an increasing trend whereas severe and ileocolonic and upper gastrointestinal disease decreased. The reasons for $\mathrm{CD}$ being mild in our region could be low rates of positive family history (negating the genetic influences), ${ }^{7}$ low smoking index of the state of Punjab $^{19}$ and delayed age of diagnosis (early onset of disease might correlate with severe disease).$^{20}$ The incidence of fistulizing perianal disease is significantly lower in our study as compared to other reports from India and Asia. ${ }^{7,21,22}$ The exact reason for this observation is not clear and needs further evaluation. One reason for under-reporting of perianal fistula could be management of such patients by surgeons and not reporting to IBD specialist.

As seen in the West, inflammatory disease (B1) was the commonest disease phenotype seen in patients with CD. Stricturing disease behavior decreased over time, however till 2010, majority of the patients with strictures had features of intesti- nal obstruction (suggesting fibrotic stricture) and needed surgical intervention ( $\mathrm{n}=36 / 40,90 \%)$.

Virtually all patients of IBD (both UC and CD) except those who are allergic/intolerant, receive 5-ASAs as initial therapy in our country. The use of thiopurines in CD remained consistent whereas it increased significantly in patients with UC. Previous reports on role of azathioprine in UC from India by the authors highlight the efficacy and safety of therapy and may have contributed to increasing trend of use of thiopurines. ${ }^{23-25}$ Cyclosporine was used for steroid refractory UC. With the increased availability, comparable efficacy and relative safety of biologics, there was a trend towards increasing use of biologics for steroid refractory UC. The proportion of CD patients having severe disease decreased over the study period. Numerically therefore, the use of biologics in CD was lower (because of fewer patients). Overall if we look however, nearly $50 \%$ of patients with severe $\mathrm{CD}$ received biologics and use of biologics was more for CD as compared to UC (Table 2).

Differentiating intestinal tuberculosis from CD is a challenge. This dilemma often leads to a therapeutic antitubercular therapy trial because CD-specific therapy can be disastrous for patients with intestinal tuberculosis. This is evident from the fact that approximately one-fifth of patients received antitubercular therapy prior to their diagnosis of CD. However, the use of antitubercular therapy declined over time in patients with CD. This could also be explained by increasing awareness, availability of better imaging modalities and a better understanding of subtle differences in natural history and presentation of the 2 diseases. This observation however needs to be interpreted with caution because the decisions were made by dedicated and experienced IBD specialists and may not be extrapolated to general practitioners.

Asian patients have a better clinical course of UC than Western patients, not only in the short term but also in the long term. The rates of surgery in UC remained stable with failure of medical management being the most common indication. On the contrary, there was a decline in surgical interventions for patients with CD. The general fall in surgery rates coupled with a rise in biologic use may suggest improved disease control. The main indication of surgery however was stricturing disease and not fistulizing or severe inflammatory disease. Because the current study did not follow the patients longitudinally, so we were unable to comment on the cumulative risk of surgery over time.

Only $0.6 \%$ of patients developed CRC in the entire cohort. This is significantly lower compared to the rates of malignancy 
in Western literature. ${ }^{26}$ Studies from India estimate a lower prevalence of CRC in UC. The lower prevalence of CRC in our cohort can be due to low risk of sporadic CRC in Indians or an inherent limitation of retrospective analysis of database records. ${ }^{27}$ Lack of implementation of an effective CRC screening programme could also have contributed to lower detection rates of malignancy.

The data from our study is based on a large cohort of more than 2,400 patients with IBD and is likely a true representation of the changing epidemiological trends in IBD. The limitations include retrospective analysis at the time of diagnosis of IBD. Patients with missing data were not included in the analysis. Hence the actual size of cohort might be underrepresented. We lack environmental, genetic and microbiome analysis that are relevant modifiers for presentation of IBD. Also, this is a hospital-based cohort study and data cannot be extrapolated to the general population.

We report changing trends of IBD with earlier age of diagnosis, increasing prevalence of $\mathrm{CD}$, male preponderance for both UC and CD, diagnosis at an early and milder stage, changing disease behavior, increasing use of thiopurines and biologics and lesser rates of malignancy over two and a half decades. Ease of diagnosis, changing environmental influences such as diet, lifestyle and industrialization are likely to have contributed to the changing trends. These need to be evaluated in wellstructured longitudinal studies. The observations from this study provide valuable information for future health service planning and are likely to determine the approach to patients with IBD in India. Development and training of IBD specialists, especially for pediatric and adolescent IBD, is a crux area that needs insight. Greater expertise in handling thiopurines and biologics is required as their use increases. Also, health economic studies would be enlightening.

\section{ADDITIONAL INFORMATION}

\section{Funding Source}

The authors received no financial support for the research, authorship, and/or publication of this article.

\section{Conflict of Interest}

Sood A is an editorial board member of the journal but was not involved in the peer reviewer selection, evaluation, or decision process of this article. No other potential conflicts of interest relevant to this article were reported.

\section{Author Contribution}

Conception and design: Sood A, Midha V. Supervision, analysis and interpretation of the data: Sood A, Midha V. Data collection: Kaur K, Singh A, Mahajan R, Singh D. Analysis and interpretation of the data: Singh A, Bansal N. Drafting of the article: Sood A, Kaur K, Singh A, Midha V, Mahajan R. Critical revision of the article for important intellectual content: Sood A, Kaur K, Singh A, Midha V, Mahajan R, Mehta V, Singh D. Final approval of the article: all authors.

\section{ORCID}

Sood A

https://orcid.org/0000-0001-6961-6389

Kaur K https://orcid.org/0000-0001-8530-9493

Singh A

Midha V

Mahajan R

Bansal N

Mehta V https://orcid.org/0000-0001-7163-0454 https://orcid.org/0000-0003-0192-3969 https://orcid.org/0000-0001-6726-6151 https://orcid.org/0000-0002-3601-4565 https://orcid.org/0000-0002-8867-9526

Singh D https://orcid.org/0000-0001-7056-503X

\section{Supplementary Material}

Supplementary materials are available at the Intestinal Research website (https://www.irjournal.org).

\section{REFERENCES}

1. Morita N, Toki S, Hirohashi T, et al. Incidence and prevalence of inflammatory bowel disease in Japan: nationwide epidemiological survey during the year 1991. J Gastroenterol 1995;30 Suppl 8:1-4.

2. Asakura K, Nishiwaki Y, Inoue N, Hibi T, Watanabe M, Takebayashi T. Prevalence of ulcerative colitis and Crohn's disease in Japan. J Gastroenterol 2009;44:659-665.

3. Sood A, Midha V, Sood N, Bhatia AS, Avasthi G. Incidence and prevalence of ulcerative colitis in Punjab, North India. Gut 2003;52:1587-1590.

4. Yang SK, Hong WS, Min YI, et al. Incidence and prevalence of ulcerative colitis in the Songpa-Kangdong district, Seoul, Korea, 1986-1997. J Gastroenterol Hepatol 2000;15:1037-1042.

5. Lai CL, Wu PC, Wong KL, Lok ASF. Clinical features of ulcerative proctocolitis in Hong Kong Chinese: a review of three decades. Am J Proctol Gastroenterol Colon Rectal Surg 1985; 36:14-19.

6. Yang SK, Yun S, Kim JH, et al. Epidemiology of inflammatory bowel disease in the Songpa-Kangdong district, Seoul, Korea, 1986-2005: a KASID study. Inflamm Bowel Dis 2008;14:542- 
549.

7. Makharia GK, Ramakrishna BS, Abraham P, et al. Survey of inflammatory bowel diseases in India. Indian J Gastroenterol 2012;31:299-306.

8. Munkholm P. Crohn's disease: occurrence, course and prognosis: an epidemiologic cohort-study. Dan Med Bull 1997;44: 287-302.

9. Langholz E. Ulcerative colitis: an epidemiological study based on a regional inception cohort, with special reference to disease course and prognosis. Dan Med Bull 1999;46:400-415.

10. Satsangi J, Silverberg MS, Vermeire S, Colombel JF. The Montreal classification of inflammatory bowel disease: controversies, consensus, and implications. Gut 2006;55:749-753.

11. Levine A, Griffiths A, Markowitz J, et al. Pediatric modification of the Montreal classification for inflammatory bowel disease: the Paris classification. Inflamm Bowel Dis 2011;17:1314-1321.

12. Best WR, Becktel JM, Singleton JW, Kern F Jr. Development of a Crohn's disease activity index. National Cooperative Crohn's Disease Study. Gastroenterology 1976;70:439-444.

13. Schroeder KW, Tremaine WJ, Ilstrup DM. Coated oral 5-aminosalicylic acid therapy for mildly to moderately active ulcerative colitis. A randomized study. N Engl J Med 1987;317:16251629.

14. Kedia S, Ahuja V. Epidemiology of inflammatory bowel disease in India: the great shift East. Inflamm Intest Dis 2017;2:102115.

15. Loftus EV Jr. Clinical epidemiology of inflammatory bowel disease: incidence, prevalence, and environmental influences. Gastroenterology 2004;126:1504-1517.

16. Moum B, Vatn MH, Ekbom A, et al. Incidence of Crohn's disease in four counties in southeastern Norway, 1990-93: a prospective population-based study. The Inflammatory Bowel South-Eastern Norway (IBSEN) Study Group of Gastroenterologists. Scand J Gastroenterol 1996;31:355-361.

17. Moum B, Vatn MH, Ekbom A, et al. Incidence of ulcerative colitis and indeterminate colitis in four counties of southeastern Norway, 1990-93: a prospective population-based study. The Inflammatory Bowel South-Eastern Norway (IBSEN)
Study Group of Gastroenterologists. Scand J Gastroenterol 1996;31:362-366

18. Loftus EV Jr, Silverstein MD, Sandborn WJ, Tremaine WJ, Harmsen WS, Zinsmeister AR. Crohn's disease in Olmsted County, Minnesota, 1940-1993: incidence, prevalence, and survival. Gastroenterology 1998;114:1161-1168.

19. International Institute for Population Sciences. National Family Health Survey (NFHS-4), 2015-16 [Internet]. c2017 [cited 2020 Jan 7]. http://www.rchiips.org/nfhs/nfhs4.shtml.

20. Solberg IC, Vatn MH, Høie O, et al. Clinical course in Crohn's disease: results of a Norwegian population-based ten-year follow-up study. Clin Gastroenterol Hepatol 2007;5:1430-1438.

21. Das K, Ghoshal UC, Dhali GK, Benjamin J, Ahuja V, Makharia GK. Crohn's disease in India: a multicenter study from a country where tuberculosis is endemic. Dig Dis Sci 2009;54:10991107.

22. Kalaria R, Desai D, Abraham P, Joshi A, Gupta T, Shah S. Temporal change in phenotypic behaviour in patients with Crohn's disease: do Indian patients behave differently from Western and other Asian patients? J Crohns Colitis 2016;10:255-261.

23. Sood A, Midha V, Sood N, Bansal M. Long term results of use of azathioprine in patients with ulcerative colitis in India. World J Gastroenterol 2006;12:7332-7336.

24. Sood A, Midha V, Sood N, Avasthi G. Azathioprine versus sulfasalazine in maintenance of remission in severe ulcerative colitis. Indian J Gastroenterol 2003;22:79-81.

25. Sood A, Kaushal V, Midha V, Bhatia KL, Sood N, Malhotra V. The beneficial effect of azathioprine on maintenance of remission in severe ulcerative colitis. J Gastroenterol 2002;37: 270-274.

26. Bopanna S, Ananthakrishnan AN, Kedia S, Yajnik V, Ahuja V. Risk of colorectal cancer in Asian patients with ulcerative colitis: a systematic review and meta-analysis. Lancet Gastroenterol Hepatol 2017;2:269-276.

27. Ferlay J, Shin HR, Bray F, Forman D, Mathers C, Parkin DM. Estimates of worldwide burden of cancer in 2008: GLOBOCAN 2008. Int J Cancer 2010;127:2893-2917. 
See "Trends of inflammatory bowel disease at a tertiary care center in northern India" on page 282-290.

Supplementary Table 1. Montreal Classification of Adult Inflammatory Bowel Disease ${ }^{1}$

\begin{tabular}{|c|c|c|}
\hline \multirow{2}{*}{ Distribution } & \multicolumn{2}{|c|}{ Montreal classification for adult UC } \\
\hline & \multicolumn{2}{|c|}{ Description } \\
\hline Proctitis & \multicolumn{2}{|c|}{ Involvement limited to the rectum (i.e., proximal extent of inflammation is distal to the recto-sigmoid junction) } \\
\hline Left sided colitis & \multicolumn{2}{|c|}{ Left-sided involvement limited to the proportion of the colon distal to the splenic flexure (analogous to "distal" colitis) } \\
\hline Extensive colitis & \multicolumn{2}{|c|}{ Extensive involvement extends proximal to the splenic flexure, including pancolitis } \\
\hline \multirow{2}{*}{ Parameters } & \multicolumn{2}{|c|}{ Montreal classification for adult CD } \\
\hline & Term & Description \\
\hline \multirow[t]{3}{*}{ Age at diagnosis } & A1 & Below 16 yr \\
\hline & A2 & Between 17 and $40 \mathrm{yr}$ \\
\hline & A3 & Above $40 \mathrm{yr}$ \\
\hline \multirow[t]{4}{*}{ Location } & L1 & lleal \\
\hline & L2 & Colonic \\
\hline & L3 & Ileocolonic \\
\hline & L4 & Isolated upper disease ${ }^{a}$ \\
\hline \multirow[t]{4}{*}{ Behavior } & B1 & Non-stricturing, non-penetrating \\
\hline & B2 & Stricturing \\
\hline & B3 & Penetrating \\
\hline & P & Perianal disease modifier ${ }^{b}$ \\
\hline
\end{tabular}

${ }^{\mathrm{L}} \mathrm{L} 4$ is a modifier that can be added to L1-3 when concomitant upper gastrointestinal disease is present.

${ }^{b} \mathrm{P}$ is added to B1-B3 when concomitant perianal disease is present.

$U C$, ulcerative colitis; CD, Crohn's disease. 
Supplementary Table 2. Paris Classification of Pediatric Inflammatory Bowel Disease ${ }^{2}$

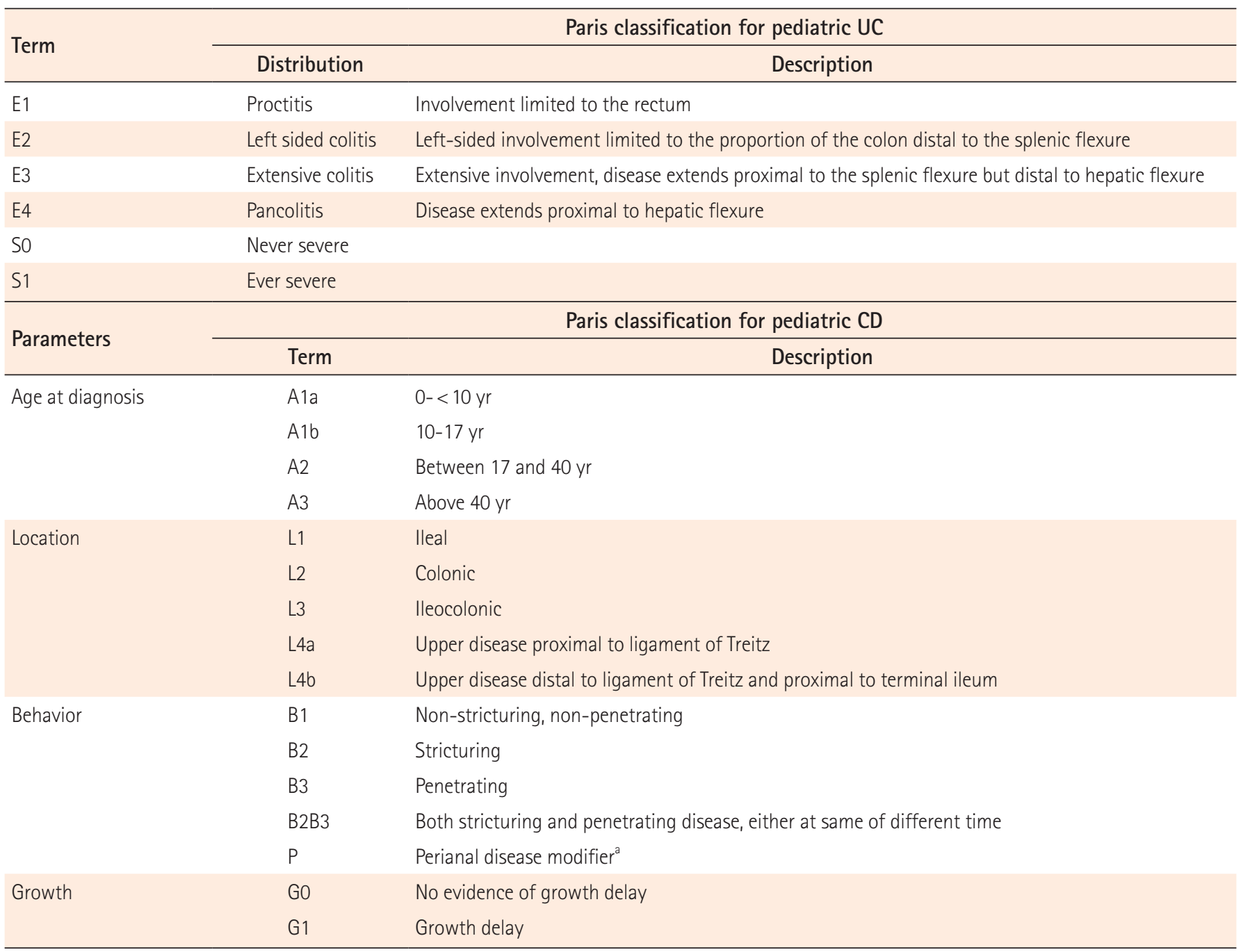

${ }^{\mathrm{a}} \mathrm{P}$ is added to $\mathrm{B} 1-\mathrm{B} 3$ when concomitant perianal disease is present.

UC, ulcerative colitis; CD, Crohn's disease.

\section{REFERENCES}

1. Satsangi J, Silverberg MS, Vermeire S, Colombel JF. The Montreal classification of inflammatory bowel disease: controversies, consensus, and implications. Gut 2006;55:749-753.

2. Levine A, Griffiths A, Markowitz J, et al. Pediatric modification of the Montreal classification for inflammatory bowel disease: the Paris classification. Inflamm Bowel Dis 2011;17:1314-1321. 